\title{
Motivação e atitudes de professores da rede pública de municípios cearenses diante do ensino de surdos
}

\author{
Germana Costa Paixã̃o* \\ Ana Cileia Pinto Teixeira Henriques** \\ Lydia Dayanne Maia Pantoja*** \\ Francisco Wagner de Sousa Paula**** \\ José Nelson Arruda Filho, Eloisa Maia Vidal*****
}

\section{Resumo}

A educação de pessoas com deficiência constitui grande desafio para os professores, considerando a formação, qualificação, políticas institucionais direcionadas e recursos humanos e materiais disponíveis. Porém, essas variáveis por si, não justificam certas dificuldades apresentadas por estes profissionais ao se depararem com esta demanda. Considerando a influência destes fatores e a importância da motivaçấo e de atitudes positivas de professores diante da educação de alunos surdos, procedeu-se estudo com 200 professores da rede pública de seis municípios cearenses a fim de identificar a motivação e atitude dos mesmos diante do ensino de alunos surdos. Realizou-se análise de conteúdo a partir dos temas levantados em questôes abertas, sendo os dados avaliados no software IRAMUTEQ por meio de análise lexicográfica com formação de nuvem de palavras. A partir destas, seis categorias foram construídas e discutidas à luz da literatura pertinente. Identificou-se pouca motivação, porém, permeadas por atitudes positivas, que, embora enfoquem a questão da capacitação como fator primordial para atuaçáo, refletem a postura de um professor que apoia a inclusão e busca novas estratégias para oportunizar a inserção deste aluno.

Palavras-chave: Atitude; Motivação; Ensino de surdos.

* Universidade Estadual do Ceará, Fortaleza, Ceará, Brasil.

** Doutoranda em Cuidados Clinicos em Saúde pela Universidade Estadual do Ceará, Fortaleza, Ceará, Brasil.

*** Doutoranda em Engenharia Civil pela Universidade Federal do Ceará, Fortaleza, Ceará, Brasil.

**** Mestrando em Cuidados Clinicos em Saúde, Fortaleza, Ceará, Brasil.

***** Professor da Universidade Estadual do Ceará, Fortaleza, Ceará, Brasil. 


\section{Motivation and attitudes of Ceara's public network teachers before the deaf education}

\section{Abstract}

The person learning disabled constitutes a challenge for teachers, considering the training, qualification, directed institutional policies and human and material resources available. However, these variables alone will not justify certain difficulties presented by these professionals when faced with this demand. Considering the influence of these factors and the importance of motivation and positive attitudes of teachers in front of the deaf students education, proceeded to study of 200 public school teachers of six Ceara's municipalities to identify the motivation and attitude before teaching of deaf students. It conducted content analysis from the issues raised in open questions, and the data evaluated in IRAMUTEQ software through lexical analysis with cloud forming words. From these six categories were constructed and discussed in light of literature. It was identified little motivation, however, permeated by positive attitudes, that although focus the issue of capacity building as a key factor for performance, reflecting the attitude of a teacher who supports the inclusion and seeks new strategies to create opportunities to insert this student.

Keywords: Attitude; Motivation; Deaf education.

\section{Introdução}

O Brasil, como signatário da Declaraçáo de Salamanca, inicia a política de inclusão na escola regular de pessoas com deficiência a partir da primeira década do século XXI. Como política pública, é inegável os avanços que a sociedade alcança no que tange a conquista de direitos sociais, mas é preciso também reconhecer que a implantação de tal política deve ser precedida de um conjunto de iniciativas de largo espectro, envolvendo especialmente os atores que se encontram na linha de frente do atendimento dessa população, que são os gestores educacionais e escolares, professores e toda a equipe de apoio escolar.

Embora a conquista do direito tenha sido assegurada por legislação específica, a educação de alunos com deficiência tem sido vista como desafio e várias são as causas elencadas por pesquisadores para esta dificuldade.

Silva (2007) aponta como fatores intervenientes o pouco conhecimento sobre métodos de estimulação em meio às necessidades educativas apresentadas e a falta de recursos aos professores e alunos. Enquanto Hassamo (2009) enfatiza a lacuna verificada entre as crenças, atitudes e práticas pedagógicas de professores.

O descompasso existente entre as políticas educacionais voltadas para a inclusáo de alunos com deficiência, em especial, alunos surdos, tem sido bastante investigado, tornando esta problemática alvo importante de discussóes e reflexóes, que ainda estão longe de alcançar um ponto comum de resoluçáo (GUARINELLO et al., 2006; RIOS; NOAVES, 2009). 
A problematização da inserção dos alunos surdos como alunos com deficiência é uma realidade e a própria legislação já se refere às pessoas surdas a partir de uma perspectiva linguística e cultural e estabelece no Art. $2^{\circ}$ do Decreto-Lei ${ }^{\circ}$ 5626/2005 que "Considera-se pessoa surda aquela que, por ter perda auditiva, compreende e interage com o mundo por meio de experiências visuais, manifestando sua cultura principalmente pelo uso da Língua Brasileira de Sinais - Libras". Nesse sentido, deve-se olhar os surdos não apenas pelo viés da educação especial, mas também por perspectivas culturais e linguísticas.

Lacerda (2006) pontua que, a partir da década de 1990, houve um esforço generalizado em busca de uma política educacional de inclusão para sujeitos com deficiência, contemplando-se também os surdos, visando, dentre outras açóes, à prática de inclusão de pessoas surdas em escolas regulares. Naquele momento, a ideia era buscar maior respeito e socialização efetiva de todos, minimizando a estigmatização e a discriminação existentes. Em contrapartida, autores como Strobel (2006) e Quadros (2003) ponderam que enquanto a língua portuguesa for principal forma de comunicação nas escolas, o verdadeiro sentido dessa tão idealizada inclusão de alunos surdos no ensino regular pode caracterizar-se muito mais como uma adaptaçấo forçada.

De fato, já passados alguns anos, constata-se que esse modelo educacional ainda não conseguiu superar as dificuldades de uma efetiva implementação e nem sempre o respeito mútuo às diferenças individuais está sendo observado, fazendo com que a comunidade surda clame por escolas bilíngues, posicionando-se em oposição à inclusão dos alunos surdos nas escolas regulares (LOPES; MENEZES, 2010).

Neste ínterim, faz-se necessário identificar fatores, não apenas relacionados à estrutura de apoio ao professor no atendimento a esta demanda, mas de considerar aspectos relacionados à motivaçáo e atitude, diante do ensino voltado para alunos surdos. Para Gil (2008), a motivação é um dos fatores mais importantes para o aprendizado e a realizaçáo de qualquer tarefa e o professor, associado às condiçóes ambientais, interfere diretamente neste processo. Enquanto a definição de atitude mais aceita é a de Fishbein e Ajzen (1975), os quais associam este termo aos conceitos de afeto, cognição e conação, ou seja, o afeto são os sentimentos de um indivíduo a respeito de um objeto; a cogniçáo relaciona-se com a crença, a opiniáo/conhecimento e o pensamento a respeito do objeto, enquanto a conação faz relação com as intençóes de comportamento e as açóes acerca do objeto. Não obstante, justifica-se a realização desta pesquisa, a fim de identificar estas questóes em realidades específicas de municípios cearenses.

Ressalta-se que, no Nordeste, segundo dados do Anuário Brasileiro da Educação Básica 2014, 89\% das crianças de 4 a 17 anos com alguma dificuldade permanente de ouvir encontram-se frequentando a escola. O documento aponta o aumento significativo do número de matrículas de alunos com deficiência no ensino fundamental regular, tendo, no ano de 2012 sido registrados 485.965 matriculados em classes comuns em detrimento de 124.129 matriculados em salas especiais e escolas especializadas (ANUÁRIO..., 2014). 
No Ceará, este número totalizou 31.626 matrículas, com 88,5\% de alunos com alguma deficiência frequentando classes comuns, o que se configura como avanço das políticas de inclusão e da valorização da integração da diversidade em salas de aulas regulares (ANUÁRIO..., 2014).

Baseando-se no aumento desta demanda, cada vez mais valorizada e impulsionada pelas políticas educacionais de atendimento aos alunos com deficiência, além de considerar a importância de fatores psicossociais que compóem e influenciam a atuação de professores neste contexto, realizou-se este estudo que buscou identificar a motivaçáo e atitude de professores das redes municipais de educaçáo de seis municípios cearenses diante do ensino de alunos surdos.

\section{Metodologia}

Trata-se de pesquisa com abordagem mista, cada vez mais valorizada no campo científico, visto que os métodos quantitativo e qualitativo se complementam e contribuem nos estudos validando os dados de pesquisa. Sampieri, Collado e Lucio (2013) definem os métodos mistos como um conjunto de processos sistemáticos e críticos de pesquisa e implicam a coleta e análise de dados quantitativos e qualitativos, assim como sua integração e discussão conjunta, para realizar inferências como produto de toda a informaçáo coletada e conseguir um maior entendimento do fenômeno em estudo.

Visando constituir perspectiva mais ampla e profunda deste fenômeno, sendo este, inclusive, pouco abordado na literatura atual, desenvolveu-se esta pesquisa com professores das redes municipais de seis cidades do estado do Ceará, da área de atuação dos polos de apoio presencial do curso de Ciências Biológicas na modalidade a distância da Universidade Estadual no Ceará, sendo estes: Beberibe, Cascavel, Maranguape, Guaramiranga, Aratuba e Capistrano.

A motivação para a realização do estudo surgiu a partir da oferta da disciplina de Língua Brasileira de Sinais (Libras) no currículo regular dos alunos do referido curso, ocorrida entre os meses de julho e setembro de 2014.

A inquietação dos discentes em conhecer como o ensino de Libras se efetivava nas escolas dos seus municípios foi o elemento motivador da pesquisa, o que culminou com a elaboraçáa de um instrumento de coleta de dados no formato de questionário a ser respondido por docentes da rede municipal de educação, que atuavam no ensino fundamental, contendo questóes referentes ao perfil sociodemográfico e de formação dos participantes do estudo, além das questóes que abordam o enfoque da pesquisa: motivaçáo e atitude diante do ensino de alunos surdos.

Para escolha do lócus de pesquisa, optou-se como critério o bom relacionamento e acesso aos gestores e professores das escolas. Estas, por sua vez, também constavam como campo de estágios curriculares do curso, o que também se constituiu como fator facilitador à entrada dos pesquisadores em campo.

A escolha dos professores participantes deu-se por amostragem por conveniência, processo não aleatório, baseado na facilidade de recrutamento, já que se busca 
um público-alvo específico, acessível por meio da escolha do local de realização da pesquisa (DAVIS; SCOTT, 2011). Consistiu como critério de inclusão que o professor atuasse no ensino fundamental das escolas, independentemente do tempo e disciplina/área de atuação, e como critério de exclusão a recusa em participar do estudo.

Todos os aspectos éticos para realização de pesquisas com seres humanos foram respeitados, tendo os pesquisados sido orientados quanto ao sigilo dos dados fornecidos, respeito à confidencialidade e garantia do uso de dados apenas para fins de pesquisa, mediante assinatura de Termo de Consentimento Livre e Esclarecido.

Os questionários foram aplicados entre agosto e novembro de 2014, e os dados analisados em dezembro de 2014 e janeiro de 2015, por meio do software IRAMUTEQ, que é um software gratuito e desenvolvido sob a lógica da open source, licenciado por GNU GPL (v2). Este viabiliza diferentes tipos de análise de dados textuais, desde a lexicografia básica (cálculo de frequência de palavras) até análises multivariadas (classificação hierárquica descendente, análises de similitude), além de organizar a distribuição do vocabulário de forma facilmente compreensível e visualmente clara (análise de similitude e nuvem de palavras) (CAMARGO; JUSTO, 2013).

Para este estudo, optou-se pela análise lexicográfica sobre o corpus textual, com a formação de nuvens de palavras para representação gráfica dos dados.

Camargo e Justo (2013) descrevem que análise textual é um tipo específico de investigação de dados feita por meio de textos, permitindo a análise de entrevistas, documentos, redaçóes, entre outros. A partir daí, é possível descrever um material produzido, seja individual ou coletivamente. Neste estudo, aplicamos a metodologia para análise de duas questôes abertas relacionadas à motivação e atitude de professores da rede básica diante do ensino de alunos surdos.

Nas análises lexicais clássicas, a qual foi escolhida para utilização no estudo, o programa identifica e reformata as unidades de texto, transformando Unidades de Contexto Iniciais (UCI) em Unidades de Contexto Elementares (UCE); identifica a quantidade de palavras, frequência média e número de hapax (palavras com frequência um); pesquisa o vocabulário e reduz das palavras com base em suas raízes (lematização); cria dicionário de formas reduzidas, identifica formas ativas e suplementares (CAMARGO; JUSTO, 2013).

Para construção da nuvem de palavras, o software agrupa as formas e as organiza graficamente em função da sua frequência. Embora seja uma análise lexical mais simples, é graficamente bastante interessante, na medida em que possibilita rápida identificação das palavras-chave de um corpus (CAMARGO; JUSTO, 2013).

Realizou-se também a análise categorial temática segundo os fundamentos de método descrito por Bardin (2011), com a construção de seis categorias que foram discutidas à luz da literatura pertinente e representadas com falas ilustrativas dos participantes do estudo, sendo estes identificados com a letra ' $P$ ' e o número de identificação dos instrumentos, para garantia do sigilo dos mesmos. 


\section{Resultados e discussão}

Participaram do estudo 200 professores da rede municipal das cidades de Cascavel, contando com 19 pesquisados (9,5\%), Beberibe com 48 (24\%), Guaramiranga com 24 (12\%), Maranguape com 83 (41,5\%), Capistrano com 20 (10\%) e Aratuba com seis $(3 \%)$, todos no estado do Ceará.

Para fins de identificação da amostra são apresentadas as características de formação e atuação dos docentes pesquisados na Tabela 1 .

Tabela 1 - Caracterização de formação e atuação de docentes de ensino fundamental sujeitos da pesquisa.

\begin{tabular}{l|c|c}
\hline Regime de Contrataçáo & $\mathbf{n}$ & $\mathbf{\%}$ \\
\hline Efetivo & 103 & 51,8 \\
\hline Temporário & 96 & 48,2 \\
\hline Titulaçáo & & \\
\hline Graduando & 73 & 2,6 \\
\hline Graduado & 114 & 37,4 \\
\hline Especialista & 2 & 1 \\
\hline Mestre & 1 & 0,5 \\
\hline Doutor & 126 & 64,3 \\
\hline $\begin{array}{l}\text { Atuaçáo em disciplinas de outra área para além da } \\
\text { formaçáo específica }\end{array}$
\end{tabular}

*As frequências simples náo contabilizam o total de pesquisados, visto ausência de respostas em algumas variáveis.

Os docentes apresentam em média 11,6 anos (com desvio padrão de \pm 8,3) de atuação docente, com mínimo de três meses e máximo de 33 anos, o que demonstra grande variabilidade de experiência de ensino na amostra estudada.

Chama a atenção a quantidade de professores com contrato temporário, o que pode significar alta rotatividade de docentes nas escolas, fato que pode prejudicar a implementação da política de atendimento ao aluno surdo.

No que diz respeito a titulação, observa-se que $58,5 \%$ dos professores já possuem cursos de pós-graduação, em nível de especialização. Registra-se 2,6\% de docentes atuando sem formação de nível superior, e 64,3\% dos docentes atuarem em disciplinas de áreas distintas da sua formação inicial, num claro descumprimento ao que estabelece a Lei de Diretrizes e Bases sobre a qualificação docente para atuação no ensino fundamental.

Visto que o foco principal do estudo remete a motivação e atitude diante do ensino de alunos surdos, foram questionadas a experiência e a formação destes para a atuação nesta modalidade, sendo estes dados apresentados na Tabela 2. 
Tabela 2 - Caracterizaçấo da experiência e formaçấo de docentes de ensino Fundamental para atuaçấo no Ensino Especial em municípios do estado do Ceará. 2014.

\begin{tabular}{l|c|c}
\hline \multicolumn{1}{c|}{ Experiência no ensino especial } & n & \% \\
\hline Sim & 52 & 26,4 \\
\hline Não3 145 & 73,6 & \\
\hline Capacitação para atuar na modalidade & & \\
\hline Sim & 59 & 30,7 \\
\hline Não & 133 & 69,3 \\
\hline
\end{tabular}

*As frequências simples não contabilizam o total de pesquisados, visto ausência de respostas em algumas variáveis.

Visualiza-se que a maioria $(73,6 \%)$ dos docentes náo possui experiência no ensino de alunos surdos, enquanto $69,3 \%$ negou ter recebido capacitação para atuar na modalidade.

A fim de avaliar o conhecimento destes docentes sobre Libras e sua formaçáo sobre esta língua, indagou-se acerca do conhecimento da língua, se realizaram algum curso ou capacitação sobre a mesma e qual tipo de formação foi realizada, sendo estes dados apresentados na Tabela 3.

Tabela 3 - Conhecimento e formaçẫo de docentes de ensino Fundamental para atuação no Ensino Especial em municípios do estado do Ceará. 2014.

\begin{tabular}{l|c|c}
\hline Conhecimento de Libras & n & \% \\
\hline Sim & 136 & 71,6 \\
\hline Náo & 54 & 28,4 \\
\hline Realizaçáo de curso de Libras & & \\
\hline Sim & 70 & 35,7 \\
\hline Não & 126 & 64,3 \\
\hline Onde se deu o contato com a Libras & 25 & 35,7 \\
\hline Disciplina cursada na Graduação & 3 & 4,3 \\
\hline Especialização & 35 & 50 \\
\hline Curso livre & 5 & 7,1 \\
\hline $\begin{array}{l}\text { Disciplina cursada na Graduação e } \\
\text { curso livre }\end{array}$ & 2 & 2,9 \\
\hline Especialização e curso livre &
\end{tabular}

*As frequências simples não contabilizam o total de pesquisados, visto ausência de respostas em algumas variáveis.

Identificou-se um perfil de professores que, embora em sua maioria $(71,6 \%)$, referisse conhecer Libras, um número significativo negou participação em cursos sobre esta língua $(64,3 \%)$, fator que poderia influenciar na motivação e em uma atitude negativa diante do ensino de alunos surdos. 
Sobre a forma de contato com a língua, 50,0\% afirma ter tido acesso em cursos livres e $35,7 \%$ nos cursos de graduação. Tal fato evidencia o esforço que o país vem fazendo no sentido de dar capilaridade a política de inclusão, na medida que, por meio de normativos legais, inclui uma disciplina nos cursos de graduaçáo e apoia e financia junto a estados e municípios, formaçôes continuadas na Libras. Embora se considere como uma iniciativa positiva por parte dos gestores públicos, cabe a indagação sobre a natureza dessas formaçóes e se, de fato, prepara os docentes para o laborioso trabalho de sala de aula com alunos deficientes incluídos.

A análise de conteúdo e lexicográfica das falas dos professores são apresentadas e discutidas por meio de recortes mais comuns para melhor compreensão das categorias geradas. Procurou-se identificar as formas de enunciação mais citadas pelos professores em resposta ao questionamento: " $\mathrm{O}(\mathrm{a})$ senhor(a) se sente motivado(a) em trabalhar com alunos surdos?"

Foram analisados 136 segmentos de texto, os quais geraram 722 ocorrências, com 308 formas, sendo estas 218 de enunciação única, que correspondem a 70,8\% das formas e $30,2 \%$ das ocorrências.

A Nuvem de Palavras 1 representa graficamente as formas que foram mais referenciadas nas falas dos professores: a falta de capacitação como justificativa: a formação como fator motivacional; a rede de apoio: elementos e atores importantes para atuação com o aluno surdo e o ensino de surdos e suas contribuiçóes para formação do professor.

Nuvem de palavras 1 - Formas de enunciação que identificam a motivação de professores das redes municipais no ensino de surdos. Fortaleza, 2015.

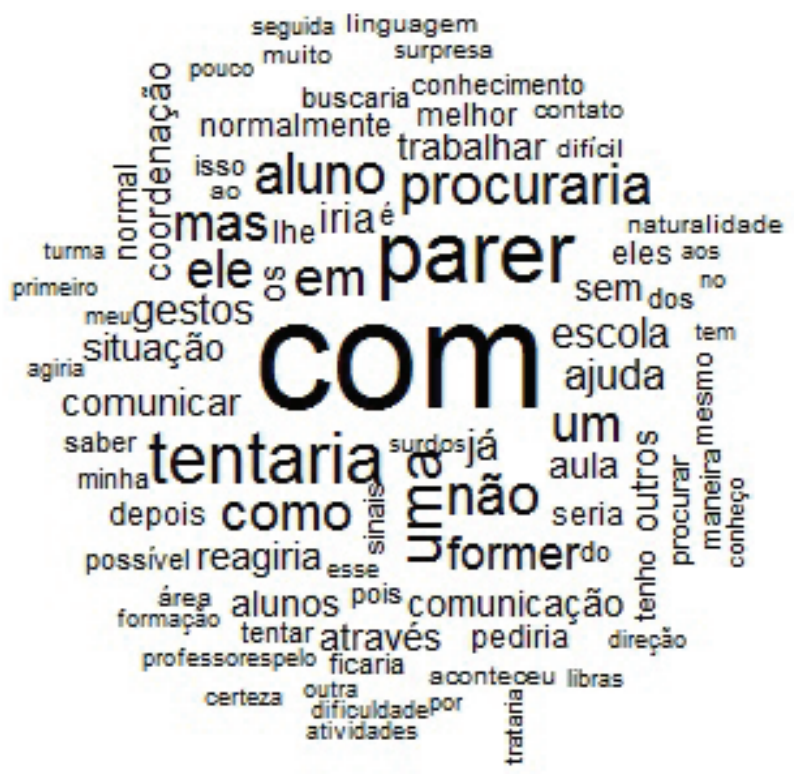




\section{A falta de capacitação como justificativa: a formação como fator motivacional}

Esta categoria retrata a maioria das justificativas de professores para ausência de motivação relacionada à falta de formação específica para atuação com alunos surdos, conforme retratado nas falas apresentadas:

\section{A falta de uma formação especí-fica, orientaçōes são dadas de forma rápida, o que} deixa a desejar (P4).

Porque para isso precisa fazer o curso e no momento náo posso fazer e na escola que trabalho já tem uma professora preparada para trabalhar com os alunos especiais (P37).

Porque não tenho preparo pedagógico para lidar com surdos (P42).

Diversos estudos vêm apontando que a formação acadêmica e profissional deficiente de professores que atuam na educação inclusiva tem sido considerada como principal barreira para uma atuação eficaz e qualificada com este perfil educacional (VALLE; GUEDES, 2003; FONTES, 2009; NAUJORKS, 2002).

Os depoimentos retratam deficiências que são apontadas por professores, em diversos estudos, como geradoras de dificuldades vivenciadas no fazer docente com alunos com deficiência auditiva como o estudo de Guarinello et al. (2006) que apontou a falta de preparo a respeito das especificidades da educação inclusiva, tais como o desconhecimento de Libras, citada por um número significativo de professores nesta pesquisa, dificuldades na articulação de programas e de políticas, citadas por Ferreira (2007), na infraestrutura e na formação, discutidas por Leonardo, Bray e Rossato (2009) e pouca orientaçáo oferecida por outros profissionais, como mencionada por um dos professores e discutida por Maia-Pinto e Fleith (2002).

Ressaltamos que ficou materializado em algumas falas que ainda existe uma dubiedade no uso dos termos "língua" e "linguagem" quando se refere a Libras, o que demonstra um conhecimento já desatualizado da temática, uma vez que esses dois conceitos não são sinônimos. Para Lacerda, 2006 a linguagem é responsável pela regulação da atividade psíquica humana, permeando a estruturação de seus processos cognitivos, sendo adquirida na vida social. Já a língua é um código linguístico compartilhado por um grupo de pessoas para efetivar a comunicação e no caso das comunidades surdas a própria Lei Federal n. 10.436, de 24 de abril de 2002 reconhece a Libras como um sistema linguístico de natureza visual-motora com estrutura gramatical própria para transmissão de ideias e fatos oriundas de pessoas surdas no Brasil.

Mesmo náo se considerando o fator primordial relacionado à motivação, é importante atentar para a importância dada pelos professores para este quesito, relacionado à segurança e domínio que os mesmos poderiam exercer ao atuarem com esta clientela e que podem constituir importantes barreiras no processo educacional deste perfil indevidamente atendido pelas políticas educacionais. 


\section{A rede de apoio: elementos e atores importantes para atuação com o aluno surdo}

A falta de apoio da escola, da Secretaria de Educação do Município e da família, foram fatores mencionados pelos professores como justificativa para ausência de motivação ao ensino de alunos surdos, como demonstrados na fala dos professores:

Porque as escolas não estão preparadas para receber esses alunos ou com qualquer outra deficiência (P3).

Não pratico mais a linguagem em Libras, os alunos que existem não conhecem Libras e a família nem conhece, nem estimula o uso, preferem os gestos (P77).

Porque a instituição que leciono não dá suporte para trabalhar com alunos surdos (P75).

Luiz et al. (2008) verificaram esta dificuldade em estudo abordando outras formas de deficiência, discutindo que a inclusão, mundialmente, tem levado a bons resultados, embora ainda haja falta de preparo dos profissionais envolvidos e da participação da família, além de uma rede de serviços que ofereça conhecimento e apoio relacionados à saúde e educação.

Diversas pesquisas como a de Valle e Guedes (2003), vêm mostrando que há entraves à expansão da educação inclusiva, e cita a falta de materiais, problemas na adaptação do ambiente e recursos, dificuldades na efetivação de políticas educacionais e problemas organizacionais.

Percebe-se que, embora se discuta a formação de professores como fator essencial, ela sozinha não é responsável pelos entraves, uma vez que, diversos fatores de contexto e, muitas vezes, externos à escola, se associam ao problema.

\section{O ensino de surdos e suas contribuições para formação do professor}

É perceptível, a partir das falas dos docentes, o quanto o contato e o ensino de alunos surdos contribui para formaçáo dos mesmos, não apenas no sentido pedagógico, mas pelo amadurecimento e engrandecimento enquanto ser humano, sendo alguns dos relatos representativos desta categoria:

Para incentivar a inclusäo desses alunos nas escolas públicas e permitir que eles tenham $o$ acesso à educação que lhes é um direito (P85).

Porque percebo neles a vontade de aprender, isso estimula as pessoas que estäo próximas. Eles têm grande sensibilidade (P89).

Além do desafio seria um prazer trabalhar com alunos tão especiais (P68).

Por aceitar desafios e gerar inclusão (P73). 
Tais representaçôes quanto ao ensino de alunos com deficiência são questionadas e discutidas em estudos cujos autores apontam que esta conjuntura pode incentivar a manifestação de postura assistencialista que isola o aluno com deficiência e não motiva o crescimento, sendo importante rever com os professores tais justificativas motivacionais (ALBUQUERQUE, 2008; SODRÉ; PLETSCH; BRAUN, 2003).

$\mathrm{Na}$ análise das respostas ao questionamento: "Como reagiria na seguinte situação: Primeiro dia de aula, o(a) senhor(a) não foi informado(a) que tem alunos surdos matriculados na escola, e, ao entrar em sala, se depara com um deles", identificaramse as formas de enunciação mais citadas pelos professores, sendo analisados 148 segmentos de texto, com 1233 ocorrências, as quais geraram 416 formas de enunciação, sendo estas 255 com entradas únicas, correspondendo a $61,3 \%$ das formas e $20,7 \%$ das ocorrências.

A Nuvem de Palavras 2 representa graficamente as formas que foram mais referenciadas nas falas dos professores, sendo estas discutidas à luz da literatura nas categorias: a solução na capacitação: a formação como fator essencial; em busca de inovação: métodos e recursos utilizados para driblar as dificuldades e em busca de apoio: recursos humanos disponiveis na escola como opção.

Nuvem de palavras 2 - Formas de enunciação que identificam as atitudes de professores das redes municipais no ensino de alunos surdos. Fortaleza, 2015.

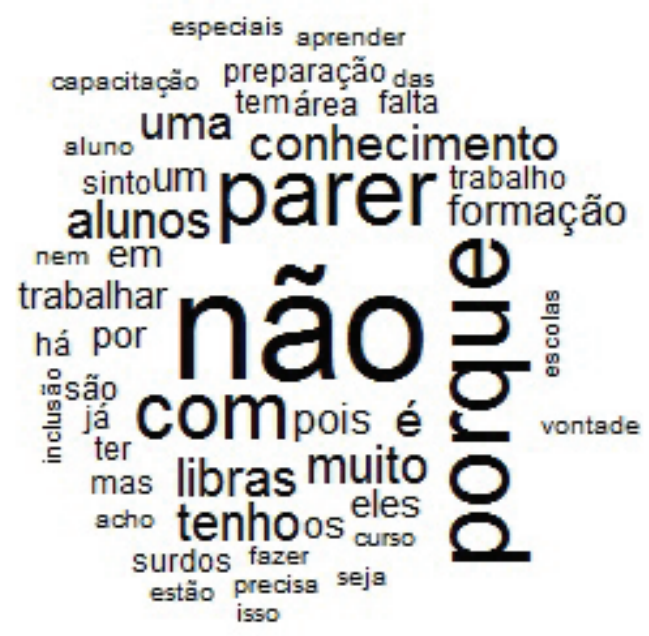

\section{A solução na capacitação: a formação como fator essencial}

Esta categoria retrata as falas referentes à importância dada pelo professor a uma formação mínima, em especial voltada ao conhecimento de Libras, para atuar com o aluno surdo, chegando alguns a afirmar a completa incapacidade de atuar 
junto a esses alunos por falta de conhecimentos básicos sobre a língua. As falas apresentam estas questóes trazidas pelos professores:

Procuraria imediatamente um curso que tivesse a formação em Libras (P1).

Simplesmente eu daria minha aula normal. Não tenho nenhuma capacitação na área. (P46).

Ficaria preocupada e tentaria me comunicar através de gestos. Depois estudar a linguagem dos sinais (P51).

Teria receio, pois o curso em que participei não me dá total segurança para trabalhar com surdos (P87).

Anjos, Andrade e Pereira (2009) discutem a implicação desta questão ao mostrarem que, diante das dificuldades apresentadas, os professores parecem não possuir uma postura positiva de enfrentamento dos desafios ligados ao ensino dos alunos com deficiência.

Por sua vez, estudos como o de Melo e Ferreira (2009) mostram que é possível citar o medo e a angústia como sentimentos presentes neste contexto, e que podem comprometer a qualidade de ensino-aprendizagem, estando na maioria das vezes, relacionados à falta de capacitação, como apontado em estudo de Rios e Novaes (2009).

Esta postura também foi refletida em falas de professores que desacreditam da possibilidade de inclusão destes alunos no modelo educacional regular, visto a falta de capacitação de professores e das estruturas escolares para tal fim:

Com certeza seria um grande susto, pois não tenho formação. Agora eu pergunto: é correto matricular um aluno surdo em uma escola onde não tem a minima condiçāo do aluno aprender (P3).

Sinceramente, um aluno surdo em uma sala de aula regular é coisa de sistema educacional do crioulo doido (P35).

Estas representaçóes foram apresentadas em pesquisas, como a de Guarinello et al. (2006), que discute acerca da imagem que o professor faz do aluno como sujeito incapaz de aprender, bem como as atitudes de exclusão da equipe escolar, que podem contribuir para reafirmar o papel de incapaz ou de doente do aluno, conforme encontraram Jurdi e Amiralian (2006) em suas pesquisas.

Melo e Ferreira (2009) discutem o quáo grave é esta questáo, apresentando que, movidos por vezes pela crença sobre a incapacidade do aluno, os profissionais tendem a reconsiderar a necessidade de investimento pedagógico e pensar se há mesmo necessidade de ensiná-lo.

Visualizou-se com esta categoria a atitude negativa de professores diante do ensino de alunos surdos, associada à deficiência de capacitação e formação inicial, que deve ser foco das políticas educacionais que buscam a efetivação de posturas inclusivas. 


\section{Em busca de inovação: métodos e recursos utilizados para driblar as dificuldades}

Esta categoria apresenta as estratégias desenvolvidas pelos professores ao se imaginarem na situaçáo colocada no instrumento, demonstrando uma atitude positiva, porém, ainda voltada para o improviso e fundamentada no fator emocional, que pode repercutir numa atuaçáo pouco efetiva e de baixa qualidade no ensino do aluno surdo. As falas abaixo representam estas questôes:

De certa forma seria uma situação dificil, dependendo da série trabalharia através de figuras, gestos de fácil entendimento (P4).

Tentarei conquistá-lo primeiro pelo carinho e atenção e gesticular algumas coisas que aprendemos e escrever bastante (P9).

Colocaria em uma cadeira próxima a mim para que ele fosse me conhecendo e aprendendo através dos gestos e leitura labial (P27).

O professor terá uma missão, assim como tem com os demais, promover a aprendizagem deste aluno, criando algumas estratégias que de alguma forma o ajude (P54).

Schemberg et al. (2009) questionam esta postura de improviso diante da atuação do aluno surdo enfatizando que, para obter sucesso no processo de escolarização dos surdos, é necessário reconhecer as peculiaridades linguísticas desses sujeitos e respeitar seus modos de construção e apropriação da língua, devendo para este fim, ter a disposição profissionais qualificados e seguros no domínio de suas atribuiçóes.

A necessidade de identificação das demandas específicas destes alunos e de uma atuação efetiva destes professores é discutida em estudos como de Maia-Pinto e Fleith (2002) no qual apontam que os alunos não estariam sendo atendidos de forma diferenciada em respeito às necessidades apresentadas e que, conforme refletem Leonardo, Bray e Rossato (2009), sua educação não teria metodologias didático-pedagógicas específicas, o que reflete a deficiência no qualificado saber docente que se espera e almeja para este público.

\section{Em busca de apoio: recursos humanos disponíveis na escola como opção}

Esta categoria representa a rede de apoio a qual o professor recorreria ao se deparar na situação de atendimento ao aluno surdo e ganham destaque nas falas as figuras da direção, coordenação e professores que atuam nas salas multifuncionais. As falas retratam esta questão:

Conversaria com meu aluno e depois, junto com a coordenação, chegaria a uma resolução (P17).

Perguntaria a turma como os demais professores agem, depois procuraria a gestão (P18).

Faço tudo para ele não perceber a minha insegurança e procuro logo a direção (P20). 
Pedia ajuda aos professores que trabalham na multifuncional (P28).

Procuraria conversar com a coordenação e a professora que está preparada para me dar instruçôes (P37).

Melo e Ferreira (2009) discutem a importância desta rede de apoio apontando que os professores procuram conhecimento teórico e formação continuada, além de profissionais responsáveis pelo atendimento, em busca de orientaçóes, sendo fundamental que tenham segurança e confiança na equipe que atua com os mesmos no contexto escolar.

A atuaçáo da gestão no apoio do professor nos contextos educacionais com alunos surdos tem sido pouco discutida na literatura, devendo ser foco de novas pesquisas que demonstrem como esta pode atuar como rede de apoio ao professor que se depara com dificuldades, não apenas no ensino de alunos surdos, mas no ensino em geral de alunos com deficiência.

\section{Considerações finais}

Identificou-se no estudo um perfil de professores com pouca ou nenhuma experiência de atuação com alunos com deficiência, o que poderia refletir na motivação e atitude destes diante do ensino de alunos surdos, conforme se visualizou nas análises das falas dos professores participantes da pesquisa.

Uma postura ainda contornada por pressupostos de caráter assistencial, emotiva, pouco capacitada e com certo improviso permeia a atitude dos docentes, embora, em sua maioria, se perceba atitude positiva diante de uma situaçáo, vista pelos docentes ainda como adversa, que é a inclusão do aluno surdo no ensino regular.

A ênfase dada à qualificação e formação específica para esta atuação demonstra a responsabilidade dos professores em prover uma formação adequada para os alunos, porém, não deve constituir foco único destes profissionais, visto que, o processo educativo envolve questôes diversas além das cognitivas.

Reforça-se a importância de novos estudos que abordem as lacunas trazidas por esta pesquisa, como a caracterização de uma formação considerada adequada pelos docentes e quais estratégias os mesmos já vêm realizando e identificando como eficazes para a adoção de posturas inclusivas, que vão além do fazer pedagógico puro.

Cabe uma indagação no que tange a política educacional de inclusão, especialmente depois da Declaração de Salamanca, em que o Brasil investiu recursos, estabeleceu normativos legais e procurou, por meio de iniciativas junto aos sistemas de ensino, matricular os alunos com deficiência nas escolas regulares: se a presente amostra de docentes de seis redes municipais mostra uma situação desalentadora no que tange minimamente ao conhecimento da Língua Brasileira de Sinais, em que medida o direito à educação está assegurado aos alunos surdos? 


\section{Referências}

ALBUQUERQUE, E. R. Decifra-me ou te devoro: os alunos com necessidade educacionais especiais nas representaçôes sociais de seus professores. In: ALMEIDA, M. A., MENDES, E. G.; HAYSHI, M. C. P. I. (Orgs.). Temas em educação especial: múltiplos olhares. Araraquara: Junqueira \& Marin, 2008. p. 202-212.

ANJOS, H. P.; ANDRADE, E. P.; PEREIRA, M. R. A inclusão escolar do ponto de vista dos professores: o processo de constituição de um discurso. Revista Brasileira de Educaçáo Especial, Marília, v. 4, n. 40, p. 116-129, 2009.

ANUÁRIO BRASILEIRO DA EDUCAÇÃO BÁSICA 2014. São Paulo: Moderna, 2014.

BARDIN, L. Análise de conteúdo. São Paulo: Ediçōes 70, 2011.

BRASIL. Lei n. 10.436/2002, de 24 de abril. Dispõe sobre a Língua Brasileira de Sinais-Libras e dá outras providências. Disponível em: <http://www.planalto.gov.br/ccivil_03/leis/2002/L10436.htm>. Acesso em: 01 nov. 2015.

Decreto-Lei no 5.626/2005, de 22 de dezembro. Regulamenta a Lei no 10.436, de 24 de abril de 2002, que dispóe sobre a Língua Brasileira de Sinais - Libras, e o art. 18 da Lei no 10.098, de 19 de dezembro de 2000. Disponível em: <https://www.planalto.gov.br/ccivil_03/_Ato2004-2006/2005/Decreto/D5626.htm>. Acesso em: 27 out. 2014

CAMARGO, B. V.; JUSTO, A. M. IRAMUTEQ: Um Software Gratuito para Análise de Dados Textuais. Temas em Psicologia, v. 21, n. 2, p. 513-518, 2013.

DAVIS, P.; SCOTT, A. Métodos de Amostragem de Pesquisa em Saúde. In: SAKS, M.; ALLSOP, J. Pesquisa em Saúde: métodos qualitativos, quantitativos e mistos. São Paulo: Roca, 2011.

FERREIRA, M. E. C. O enigma da inclusão: das intençôes às práticas pedagógicas. Educação e Pesquisa, São Paulo, v. 33, n. 3, p. 543-560, 2007.

FISHBEIN, M.; AJZEN, I. Belief, attitude, intention and behavior: an introduction to theory and research. Reading: Addison-Wesley, 1975.

FONTES, R. S. Ensino colaborativo: uma proposta de educaçáo inclusiva. Araraquara: Junqueira \& Marin, 2009.

GIL, A. C. Didática do ensino superior. 1 ed. 3 reimpr. São Paulo: Atlas, 2008.

GUARINELLO, A. C. et al. A inserçáo do aluno surdo no ensino regular: visão de um grupo de professores do Estado do Paraná. Revista Brasileira de Educaçáo Especial, Marília, v. 12, n. 3, p. 317-330, 2006.

HASSAMO, I. C. S. Relaçáo entre crenças, atitudes e práticas pedagógicas de professores na inclusão de alunos com deficiência mental. 2009. 65f. Dissertação (Mestrado em Psicologia da Educação e da Orientação). Faculdade de Psicologia e de Ciências da Educação, Universidade de Lisboa, Lisboa, 2009.

JURDI, A. P. S.; AMIRALIAN, M. L. T. M. A inclusão escolar de alunos com deficiência mental: uma proposta de intervenção do terapeuta ocupacional no cotidiano escolar. Estudos de Psicologia, Campinas, v. 23, n. 2, p. $191-202,2006$.

LACERDA, C. B. F. A inclusão escolar de alunos surdos: o que dizem alunos, professores e intérpretes sobre essa experiência. Cad. Cedes, campinas, v. 26, n. 69, p. 163-184, 2006.

LEONARDO, N. S. T.; BRAY, C. T.; ROSSATO, S. P. M. Inclusão escolar: um estudo acerca da implantação da proposta em escolas de ensino básico. Revista Brasileira de Educaçáo Especial, Marília, v. 15, n. 2, p. 289 306, 2009.

LOPES, M. C.; MENEZES, E. C. P. Inclusāo de alunos surdos na escola regular. Cadernos de Educaçáo, v. 36, n. 1, p. 69-90, 2010.

LUIZ, F. M. R. et al. A inclusão da criança com Síndrome de Down na rede regular de ensino: desafios e possibilidades. Revista Brasileira de Educaçăo Especial, Marília, v. 14, n. 3, p. 97-508, 2008.

MAIA-PINTO, R.R.; FLEITH, D.S. Percepçấo de professores sobre alunos superdotados. Estudos em Psicologia, Campinas, v. 19, n. 1, p. 78-90, 2002.

MELO, F. R. L. V.; FERREIRA, C. C. A. O cuidar do aluno com deficiência física na educaçăo infantil sob a ótica das professoras. Revista Brasileira de Educaçáo Especial, Marília, v. 15, n. 1, p. 121-140, 2009. 
NAUJORKS, M. I. Stress e inclusão: indicadores de stress em professores frente à inclusão de alunos com necessidades educacionais especiais. Revista Cadernos de Educação Especial, Santa Maria, v. 20, p.117-125, 2002.

QUADROS, R. M. Situando as diferenças implicadas na educação de surdos: inclusão/exclusão. Ponto de Vista, Florianópolis, n. 05, p. 81-111, 2003.

RIOS, N. V. F.; NOVAES, B. C. A. O processo de inclusão de crianças com deficiência auditiva na escola regular: vivências de professores. Revista Brasileira de Educaçáo Especial, Marília, v. 15, n. 1, p. 81-98, 2009.

SAMPIERI, R. H.; COLLADO, C. F.; LUCIO, M. P. B. Metodologia de Pesquisa. 5. ed. Porto Alegre: Penso, 2013.

SCHEMBERG, S. Educação escolar e letramento de surdos: reflexões a partir da visão de pais e professores. Revista da Sociedade Brasileira de Fonoaudiologia. São Paulo, v. 14, n. 3, p. 437-437, 2009.

SILVA, K. F. W. Inclusáo escolar de alunos com deficiência mental: possíveis causas do insucesso. 2007.185f. Dissertação (Mestrado em Educação). Faculdade de Educação, Programa de Pós- Graduação em Educação, Universidade Federal do Rio Grande do Sul, Porto Alegre, 2007.

SODRÉ, J.; PLETSCH, M. D.; BRAUM, P. A. Formação inicial e continuada de recursos humanos para a prática docente frente à educação inclusiva. In: NUNES SOBRINHO, F. P. (Org.). Inclusáo educacional pesquisa e interfaces. Rio de Janeiro: Livre Expressão, 2003.

STROBEL, K. L. A visão histórica da in(ex)clusão dos surdos nas escolas. Educação Temática Digital. Campinas, v. 7, n. 2, p. 245-254, 2006.

VALLE, M. H. F.; GUEDES, T. R. Habilidades e competências do professor frente à inclusão. In: NUNES SOBRINHO, F.P. (Org.). Inclusáo educacional 6n - pesquisa e interfaces. Rio de Janeiro: Livre Expressão, 2003.

\section{Correspondência}

Germana Costa Paixão - Universidade Estadual do Ceará, Centro de Ciências da Saúde, Coordenação de Ciências Biológicas. Avenida Paranjana 1700, Itaperi, CEP: 60000-000, Fortaleza, Ceará, Brasil.

E-mail: germana.paixao@uece.br - anacileia.henriques@uece.br - pantojalydia@gmail.com - wagnercrt@hotmail.com - nelson.arruda@uece.br - eloisamvidal@yahoo.com.br

Recebido em 17 de julho de 2015

Aprovado em 03 de novembro de 2015 